\title{
The pro-opiomelanocortin genes in rainbow trout (Oncorhynchus mykiss): duplications, splice variants, and differential expression
}

\author{
E H Leder and J T Silverstein \\ National Center for Cool and Cold Water Aquaculture, Agricultural Research Service, United States Department of Agriculture, Kearneysville, \\ West Virginia 25430, USA \\ (Requests for offprints should be addressed to E H Leder; Email: eleder@nccwa.ars.usda.gov)
}

\begin{abstract}
Pro-opiomelanocortin (POMC) is a precursor for several important peptide hormones involved in a variety of functions ranging from stress response to energy homeostasis. In mammals and fish, the POMC-derived peptide $\alpha$-melanocyte stimulating hormone (MSH) is known to be involved in appetite suppression through its interaction with melanocortin-4 receptors. The details of energy homeostasis in fishes are beginning to be elucidated and many of the genes involved in mammalian neuroendocrine signaling pathways are being discovered in fish. In salmonid fishes such as the rainbow trout, genome duplication adds another degree of complexity when trying to compare gene function and homology with other vertebrates. This is true of the POMC gene. Two copies of the POMC gene were previously identified, A and B, presumably resulting from the salmonid duplication. However, while investigating POMC involvement in the feeding response of rainbow trout, a second copy of POMC-A
\end{abstract}

was discovered which is more likely the result of the salmonid duplication and suggests that POMC-B is a duplicate resulting from the earlier teleost duplication prior to tetrapod divergence. The duplicated POMC-A had five deleted amino acids, five inserted amino acids, and 39 amino acid differences from the published POMC-A. In addition to the duplicate POMC-A, a splice variant of the published POMC-A sequence was also identified. Quantitative real-time PCR assays were developed for the different POMC transcripts, and expression was examined in a variety of tissues. Expression of POMC transcripts was highest in the pituitary for all POMC genes, but varied among other tissues for POMC-A1, POMC-A2, POMC-A2s, and POMC-B. POMC-A1 was the only transcript to respond significantly to food deprivation.

Journal of Endocrinology (2006) 188, 355-363

\section{Introduction}

Pro-opiomelanocortin (POMC) is an important precursor for several peptide hormones involved in a broad variety of functions, ranging from the stress response to energy homeostasis. POMC is expressed mainly in the pituitary, but expression also occurs in the hypothalamus and peripheral tissues (Civelli et al. 1982). The POMC polypeptide undergoes post-translational processing in a tissue-specific manner to yield biologically active peptide hormones (Smith \& Funder 1988).

Portions of the POMC gene are highly conserved and have been identified in most groups of vertebrates from fish to mammals, including lamprey, shark, lungfish, and coelacanth. In tetrapods and lungfish, POMC peptides consist of adrenocorticotropin (ACTH), melanotropins $(\alpha, \beta$, and $\gamma-\mathrm{MSH})$, corticotrophin-like intermediate lobe peptide (CLIP), lipotropins ( $\beta$ and $\gamma-\mathrm{LPH})$, and $\beta$-endorphin (Nakanishi et al. 1979, Amemiya et al. 1999a). However, chondricthyans have an additional melanotropin (ס-MSH) (Amemiya et al. 1999b) and teleosts lack $\gamma$-MSH (Kitahara et al. 1988, Lee et al. 1999). In agnathans, one of the oldest extant vertebrates, the POMC peptides are encoded by two separate genes called pro-opiomelanotropin (POM) and pro-opicortin (POC) (Takahashi et al. 1995). POM encodes peptides similar to $\alpha-\mathrm{MSH}, \beta-\mathrm{MSH}$, and $\beta$-endorphin, and POC encodes peptides ACTH and a different $\beta$-endorphin.

POMC has a role in energy homeostasis in mammals through the action of the peptide $\alpha-\mathrm{MSH}$. As fat stores increase (energy surplus), leptin is secreted from adipocytes (Friedman \& Halaas 1998) and circulates to the brain where it enters the hypothalamus through a saturable transport mechanism (Banks et al. 1996). In mammals, POMC neurons in the hypothalamus contain the leptin receptor (Cheung et al. 1997). The binding of leptin to the leptin receptor activates the transcription of POMC and cocaine- and amphetamine-regulated transcript (CART) (Elias et al. 1998). The peptide $\alpha$-MSH from the processed POMC transcript binds to melanocortin receptor 4 in the 
hypothalamus and stimulates other neuropeptides and second messenger systems that reduce food intake (Schwartz et al. 2000).

The details of energy homeostasis in fishes are beginning to be elucidated and many of the genes involved in mammalian neuroendocrine signaling pathways are being discovered in fish. There is evidence that neuropeptide Y, agouti-related peptide, $\alpha-\mathrm{MSH}, \mathrm{CART}$, leptin, and ghrelin all have a role in appetite regulation in fish (for review see Volkoff et al. 2005). In salmonid fishes such as the rainbow trout, genome duplication has added another degree of complexity to the determination of gene function and homology with other vertebrates. This is true of the POMC gene. Two copies of the POMC gene were previously identified, POMC-A and POMC-B, and were presumed to have resulted from the salmonid genome duplication (Salbert et al. 1992). However, while investigating POMC for its role in the feeding response of rainbow trout, three distinct cDNA transcripts were identified for POMC-A. Two of these POMC-A transcripts are encoded by separate genes which are likely the result of the salmonid duplication rather than POMC-A and POMC-B. The present study focuses on the sequence divergence and expression patterns of the POMC genes of rainbow trout, including both POMC-A and POMC-B transcripts.

\section{Materials and Methods}

\section{Fish care}

Rainbow trout used in this study were all reared at the National Center for Cool and Cold Water Aquaculture (NCCCWA) in Kearneysville, WV, USA. Except where noted in the following experiments, fish were housed in 4 foot diameter tanks, and fed commercial trout food at approximately $1-2 \%$ of body weight per day. Lighting approximated natural photoperiod. Fish care and experimentation followed the guidelines outlined by the USDA and the NCCCWA Animal Care and Use Committee.

\section{Genomic and $c D N A$ sequence determination}

Rainbow trout POMC sequences from Genbank were used to search the rainbow trout gene index http:// www.tigr.org $/$ tigr-scripts $/$ tgi $/ T$ _index.cgi?species $=r_{-}$trout (Rexroad et al. 2003). Two separate expressed sequence tag (EST) contigs, TC89514 and TC86162, were identified with a high degree of similarity to POMC-A, and one EST contig was identified for POMC-B, TC72094. In order to obtain full-length clone sequences and verify identity, bacterial clones containing ESTs were picked from glycerol stocks and grown overnight in Luria-Bertani media $(5 \mathrm{~g} / \mathrm{L} \mathrm{NaCl}, 5 \mathrm{~g} / \mathrm{L}$ yeast extract and $10 \mathrm{~g} / \mathrm{L}$ tryptane). Plasmid DNA was isolated from cell culture using QIAprep Miniprep Kit (Qiagen). Cleaned plasmids were sequenced in both directions to obtain full length sequences using an ABI 3100 automated DNA sequencer (Applied Biosystems, Foster City, CA, USA). Sequences were edited and aligned using Sequencher version 4.1.4 (Gene Codes Corporation, Ann Arbor, MI, USA).

To examine genomic DNA for intron differences that would suggest duplicated genes, consensus primers from the two POMC-A EST clones were designed within the second and third exon and were used to amplify across the second intron of genomic DNA. Primers for POMC-B were also designed to amplify a similar region (Table 1). Genomic DNA was extracted from rainbow trout liver using Epicentre's Masterpure DNA extraction kit (Epicentre, Madison, WI, USA). Amplification reactions contained $100 \mathrm{ng}$ total DNA, $0.32 \mu \mathrm{M}$ each primer, $1.5 \mathrm{mM} \mathrm{MgCl} 2,200 \mu \mathrm{M}$ each dNTP, $1 \times$ PCR buffer, and 2 units Taq polymerase (Invitrogen, Carlesbad, CA, USA). Thermal cycler profiles consisted of an initial denaturation step of $3 \mathrm{~min}$ at $94^{\circ} \mathrm{C}$, followed by 35 cycles of $30 \mathrm{~s}$ at $94^{\circ} \mathrm{C}, 35 \mathrm{~s}$ at annealing temperature of $60^{\circ} \mathrm{C}$, and $90 \mathrm{~s}$ extension at $72^{\circ} \mathrm{C}$. Products were purified for cloning using QIAquick PCR Purification Kit (Qiagen). Cleaned PCR products were cloned using pGEM-T Easy cloning kit (Promega). Plasmid DNA was isolated from cell culture, sequenced, and analyzed as above. Upon initial sequence analysis, sequences corresponding to EST contig TC89514 were found, but no genomic clones corresponding to TC86162 were identified. Another primer set specific to this clone and corresponding to a shorter sequence fragment was used to amplify genomic DNA. Genomic DNA was amplified, cloned, and sequenced as above. This amplification yielded a sequence corresponding to TC86162. These genes will now be referred to as POMC-A1 (TC86162) and POMC-A2 (TC89514). The intron amplified from the POMC-A1 gene was approximately twice as long as the intron sequenced from POMC-A2 and may have been the reason these fragments were lacking from initial genomic amplification.

To ensure that both copies identified from the trout gene index and genomic DNA were expressed, a portion of the POMC gene was amplified from cDNA using POMCa-9 forward (F) and POMCa-408 reverse (R) (Table 1). Total RNA was extracted from whole heads of rainbow trout fry (2 months post-hatch). Whole heads were used to ensure that the pituitary and hypothalamus were included since dissecting the pituitary and brain can be difficult because of the small size of the fish at that age. Total RNA was extracted by means of Tri Reagent (Sigma) using the manufacturer's protocol. RNA was treated with DNase (Promega) and re-extracted. Firststrand cDNA was synthesized by allowing $1 \mu \mathrm{g}$ random primers (Promega) to anneal to $2 \mu \mathrm{g}$ RNA for $5 \mathrm{~min}$ at $70{ }^{\circ} \mathrm{C}$ in a final volume of $10 \mu \mathrm{l}$ and then adding $15 \mu \mathrm{l}$ 
Table 1 List of names and sequences for primers and probes used in this study. Information includes which transcript or gene is amplifed and whether the primer was used to amplify genomic or cDNA products for sequencing or for real-time PCR assays (SYBR or TaqMan)

Primer sequence $\left(5^{\prime}-3^{\prime}\right)$

\section{Primer name}

POMC-A-9-F

POMC-A-408-R

POMC-B-20-F

POMC-B-399-R

POMC-A1-71-F

POMC-A1-175-R

POMC-A1-495-F

POMC-A2-174-F

POMC-A1-80-F

POMC-A2-341-F

POMC-A2-601-R

POMC-A2s-128-F

POMC-A2s-293-F

POMC-A2s-probe

POMC-B-512-F

POMC-B-590-R

EF1 $\alpha-F$

EF1 $\alpha-R$

TCCTGCGTGGTTATTGGCTGT
TGCCCAGCTCTCGTCTCATC
TGTGTGCGCCCTGGCTGT
GGAAAGGTGCCCTCGGAGGAG
GGGAGAATCCTCGCTGTCAAGA
GAGTTGGGTTGGAGATGGACCTC
GAGTCCCATAAGCCGATGCAAA
AAGAGAGCGGTACGACTGAGTG
CTCGCTGTCAAGACCTCAACTCT
TCCCCGTCAAGGTGCATCT
TCAGTGCCCAGCTCTGGTCT
CGTTCTGACCTCACCACCAA
ATGGAGTAGGAACGCTTGGC
CGTCAAGCAGAACAGTGT
CCAGAACCCTCACTGTGACGG
CCTGCTGCCCTCCTCTACTGC
GGGCAAGGGCTCTITCAAGT
CGCAATCAGCCTGAGAGGT

Transcript/gene

POMC-A1 and A2 POMC-A1 and A2 POMC-B

POMC-B

POMC-A1

POMC-A1

POMC-A1

POMC-A2

POMC-A1

POMC-A2

POMC-A2

POMC-A2s

POMC-A2s

POMC-A2s

POMC-B

POMC-B

EF1 $\alpha$

EF1 $\alpha$
Function

Initial cDNA and genomic sequencing
Initial cDNA and genomic sequencing
Initial cDNA and genomic sequencing
Initial cDNA and genomic sequencing
Second genomic sequencing
Second genomic sequencing and SYBR Green assay
Internal genomic sequencing
Internal genomic sequencing
SYBR Green assay
SYBR Green assay
SYBR Green assay
TaqMan assay
TaqMan assay
TaqMan assay
SYBR Green assay
SYBR Green assay
SYBR Green assay
SYBR Green assay

$\mathrm{EF}$, elongation factor.

reverse transcription reaction mix (200 units of Maloney Murine Leukemia Virus-Reverse Transcriptase (MMLV_T), $12.5 \mathrm{mM}$ each dNTP, 25 units RNasin and $1 \times$ reverse transcriptase reaction buffer) and incubating at $37^{\circ} \mathrm{C}$ for $1 \mathrm{~h}$. The PCR product resulting from the cDNA amplification was cloned as above and several clones were sequenced. Three of the sequenced clones yielded a splice variant of POMC-A2, which is referred to as POMC-A2s (for splice variant or short form) below.

\section{Phylogenetic relationships}

Amino acid sequences of POMC genes from humans and fish species were obtained from Genbank to determine the relationships of the rainbow trout POMC genes within the context of other POMC sequences. Rainbow trout POMC-A and POMC-B were used to search the Genbank protein database. Although there were many BLAST hits, teleost fish with multiple POMC genes were primarily selected. Sequences were aligned using Multalin (Corpet 1988) and ClustalX (Thompson et al. 1997) using default settings and further adjusted manually. The neighbor-joining algorithm of Saitou \& Nei (1987) was used to construct a tree using phylogenetic analysis using parsimony (Swofford 1998). Support for the tree branches was estimated by bootstrapping (1000 replicates).

\section{Tissue-specific expression}

A tissue panel consisting of pituitary, stomach, intestine, ovary, liver, red and white muscle, liver, spleen, anterior kidney, eye, skin, and brain tissues (hypothalamus, telencephalon, optic tectum, cerebellum) was created by pooling each of these tissues from five female juvenile rainbow trout (approximately 6 months post-hatch, $150 \mathrm{~g}$ ). Fish were killed upon removal from the tank by immersion in $15 \mathrm{mg} / \mathrm{l}$ tricaine methane sulfonate (MS-222) and decapitation. Tissues were promptly removed and placed in liquid nitrogen. RNA was extracted and first-strand cDNA was created as described above. Primers specific to each transcript were designed and used for real-time PCR (Table 1). For POMC-A1, POMC-A2, and POMC-B, real-time analyses were conducted using SYBR Green assays. Reactions were carried out in triplicate and each consisted of $0 \cdot 25 \mu$ of the first-strand cDNA reaction, $0.5 \mu \mathrm{M}$ each primer, and $1 \times$ SYBR Green PCR Master Mix (Applied Biosystems, Foster City, CA, USA) in a volume of $15 \mu \mathrm{l}$. Thermal cycling profile was $50^{\circ} \mathrm{C}$ for $2 \mathrm{~min}, 95^{\circ} \mathrm{C}$ for $10 \mathrm{~min}$ and 40 cycles of $95^{\circ} \mathrm{C}$ for $30 \mathrm{~s}$, $60{ }^{\circ} \mathrm{C}$ for $20 \mathrm{~s}, 72{ }^{\circ} \mathrm{C}$ for $30 \mathrm{~s}$, and $79 \cdot 5^{\circ} \mathrm{C}$ for $10 \mathrm{~s}$. Data collection took place between the $79.5^{\circ} \mathrm{C}$ step and the denaturation step to avoid measurement of primer dimer artifacts (Ramos-Payan et al. 2003). A final dissociation step was performed to assess the specificity of the reaction.

Due to the difficulty of preferentially amplifying the splice variant, POMC-A2s, a 6-carboxyfluorescein-labeled probe was designed that extends across the splice junction and a TaqMan assay was used to amplify the transcript. Reactions were carried out as above except the TaqMan PCR Master Mix (Applied Biosystems) was used instead of SYBR Green PCR Master Mix and $450 \mathrm{pmol}$ of the probe was added to the reaction. The thermal cycling profile was $50{ }^{\circ} \mathrm{C}$ for $2 \mathrm{~min}, 95^{\circ} \mathrm{C}$ for $10 \mathrm{~min}$, and 40 cycles of $95^{\circ} \mathrm{C}$ for $30 \mathrm{~s}, 60{ }^{\circ} \mathrm{C}$ for $1 \mathrm{~min}$. 


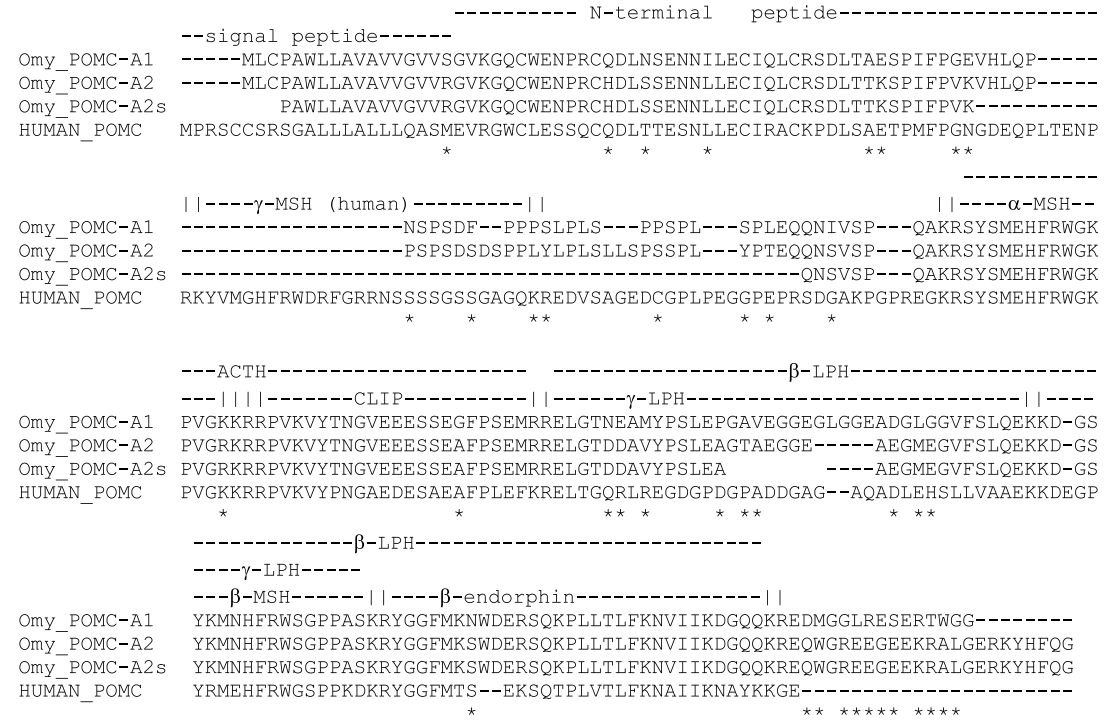

Figure 1 Protein alignment of POMC-A sequences for rainbow trout (Omy) and human POMC sequence. Signal peptide, $\mathrm{N}$-terminal peptide, and the biologically active peptides $(\alpha-, \beta-$, and $\gamma-\mathrm{MSH}, \mathrm{ACTH}, \mathrm{CLIP}, \beta$ - and $\gamma$-LPH, and $\beta$-endorphin) are indicated. Dropped lines indicate di-basic cleavage sites. Intron 3 for POMC-A2s is indicated as a gap in the alignment where it varies from POMC-A2. Asterisks under the sequence indicate amino acid differences between POMC-A1 and POMC-A2.

To account for differences in cDNA template amount or quality, SYBR Green assays for elongation factor $1 \alpha$ $(E F 1 \alpha)$ were run for each cDNA template on each plate. A threshold value of $0 \cdot 2$ was chosen because it was above background fluorescence and in the exponential phase of amplification for all assays. Efficiency curves for all assays were produced using serial dilutions of pituitary cDNA.

The absolute quantification method (Applied Biosystems) was used to determine mRNA abundance among tissues using a standard curve of linearized plasmid DNA from EST clones for POMC-A1, POMC-A2, and POMC-A2s. The POMC-B EST was truncated and did not contain the primers used for the real-time PCR assay, so a fragment containing that portion of POMC-B was amplified and cloned into pGEM-T easy (Promega) for use as a standard. The slopes of the efficiency curves were similar to the slopes of the plasmid standard curves for each primer set, indicating similar PCR reaction efficiency for the plasmid standard and the cDNA template.

\section{Response to food deprivation}

Thirty-two rainbow trout of approximately $300-400 \mathrm{~g}$ were divided into two 2 foot tanks. Fish were acclimated to the tanks for 2 weeks and fed daily. After acclimation, food was withheld from one tank. Eight fish were sampled from each tank after 14 days. After 28 days the remaining eight fish from each tank were sampled. Fish were killed, hypothalamic tissue was removed and stored, and RNA was extracted as above. First-strand cDNA was created from $2 \mu \mathrm{g}$ RNA and real-time PCR reactions were performed on the hypothalamic tissue in the same manner as described above. Efficiency curves for all assays were produced using serial dilutions of pituitary cDNA. The relative standard curve method (Applied Biosystems) was used to compare relative mRNA abundance among treatments with expression normalized to EF1 $\alpha$ and calibrated to hypothalamus expression in the fed samples for each gene. Statistical significance between fed and food-deprived treatments was determined by comparing the means of the normalized values for each treatment using a Student's $t$-test.

\section{Results}

Initial BLAST searches of the rainbow trout gene index revealed three distinct consensus sequences. After further analysis, one was identical to the Genbank sequence of POMC-A (CAA49466) and another was identical to POMC-B (CAA49467). The third was more similar to POMC-A than POMC-B, but the deduced amino acid sequence of the coding sequence had 39 amino acid differences, five deleted amino acids, and five inserted amino acids (Fig. 1). Sequencing of the EST clones confirmed these sequences, and genomic DNA sequencing further illustrated their distinction as the two genes had different intron sequences.

Cloning and sequencing of PCR-amplified cDNA for these genes revealed an additional transcript for POMC-A2. 

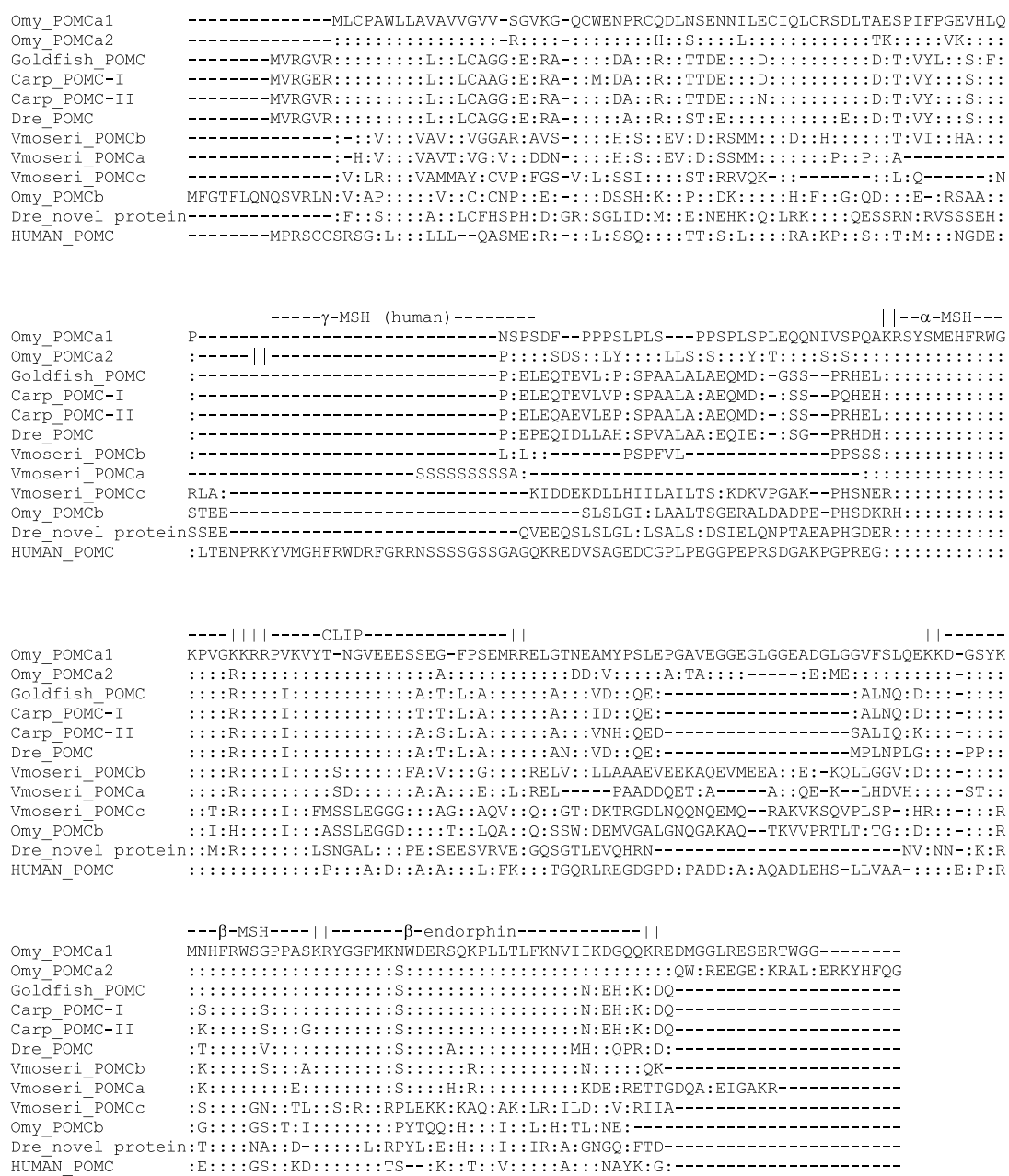

Figure 2 Protein alignment of POMC sequences for rainbow trout (Omy), zebrafish (Dre), goldfish, carp, barfin flounder (Vmoseri), and human. Gaps in the alignment are represented by the symbol - , and amino acid residues that are identical to rainbow trout POMC-A1 are represented by the symbol :. Dropped lines indicate di-basic cleavage sites. Genbank accession numbers for the amino acid sequences are: human, CAA24754; goldfish, CAD24030; carp POMC-I, CAA74968; carp POMC-II, CAA74967; zebrafish, AAO64394; zebrafish novel protein, CAl11753; barfin flounder POMCa, BAB18467; barfin flounder POMCb, BAB18468; barfin flounder POMCc, BAB18469.

A splice variant, POMC-A2s, was missing $102 \mathrm{bp} \mathrm{(34}$ deduced amino acids) from the $\mathrm{N}$-terminal peptide just prior to the cleavage site for $\alpha-\mathrm{MSH} / \mathrm{ACTH}$ (Fig. 1). Other than the deletion, the sequences were identical.

Human POMC was chosen to represent the mammalian lineage and to orient the tree, but the other species were chosen from the teleost lineage in order to determine relationships within this taxon. Because of recent debate concerning gene and genome duplication, particularly within teleosts, teleost species with multiple copies of POMC were of specific interest. Barfin flounder (Verasper moseri) had three separate POMC genes listed in Genbank, BAB18467, BAB18468, and BAB18469, and two POMC genes were identified in Carp (Cyprinus carpio), CAA74967 and CAA74968. A zebrafish sequence (CAI11753) annotated in Genbank as a 'novel protein similar to proopiomelanocortin' was identified that appears to be a POMC gene and is most likely the POMC-like peptide identified by Gonzales-Nunez et al. (2003). Amino acid sequences of human and teleost POMC genes showed the highest homology through the $\alpha-\mathrm{MSH}$ coding region, but CLIP, $\beta-\mathrm{MSH}$, and $\beta$-endorphin coding regions were also very similar (Fig. 2).

Neighbor-joining revealed a distinct difference between POMC-B-like sequences and POMC-A-like sequences in rainbow trout, and both zebrafish and 


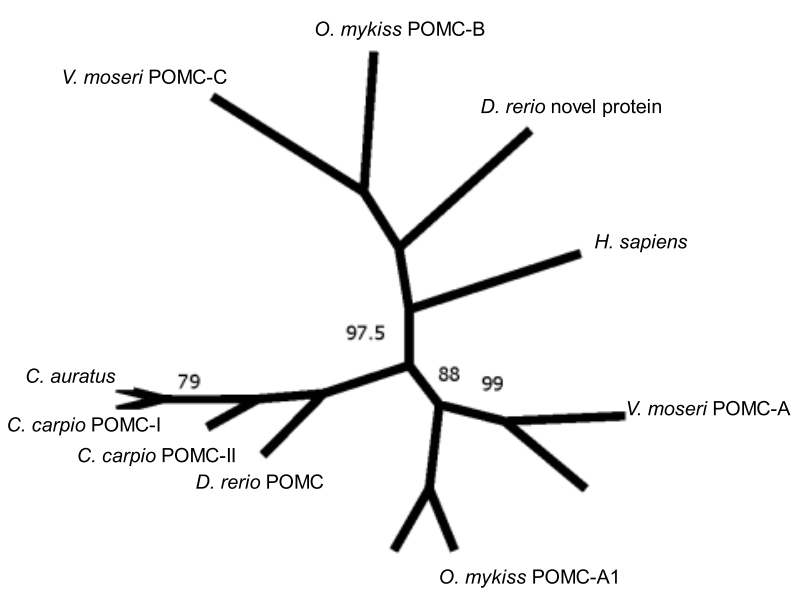

Figure 3 Neighbor-joining tree based on sequence alignment from Fig. 2. Numerical values indicate the percentage of times that the branch was supported out of 1000 bootstrap replicates. All unmarked nodes had $100 \%$ support. POMC nomenclature is as presented in Genbank and is not representative of evolutionary relationship or similarity.

barfin flounder had sequences similar to both types (Fig. 3). Conversely, the carp duplicates, POMC-I and POMC-II, were closely related and were both POMC-A like.

All POMC transcripts had the highest expression in the pituitary with more than a million copies of transcript per $0 \cdot 02 \mu \mathrm{g}$ RNA (Fig. 4). The second highest amount of transcript was found in the hypothalamus for POMC-A1, A2, and A2s. POMC-B had approximately 100 copies in the telencephalon and less than 100 copies in the hypothalamus. Expression in peripheral tissues varied for the POMC transcripts. POMC-A1, POMC-A2, and POMC-B were detectable but rare in all peripheral tissues examined; in most cases there were less than 20 copies of transcript per $0.02 \mu \mathrm{g}$ RNA. POMC-A2s was not detected in the liver, ovary, white muscle, skin, stomach, or intestine. Expression of POMC-A1 was approximately ten times greater than POMC-A2 in the pituitary, hypothalamus, and ovary.

There was no significant difference in expression in the hypothalamus between fed and food-deprived fish after 14 days for any of the POMC transcripts (data not shown). After 28 days of food deprivation, only POMC-A1 showed a significant reduction in expression in the food deprived fish (Fig. 5), with expression levels at about 50\% of the fed animals.

\section{Discussion}

The presence of three distinct mRNA types resulting from three genes suggests there are at least three functional POMC genes in rainbow trout. Previously, rainbow trout POMC-A and POMC-B were attributed to the salmonid genome duplication (Salbert et al. 1992). However, based on the duplicated POMC-A identified here and the occurrence of two other teleost POMC genes (barfin flounder POMCc and zebrafish novel protein) similar to rainbow trout POMC-B, it appears that POMC-A and POMC-B are the result of the teleost genome duplication.

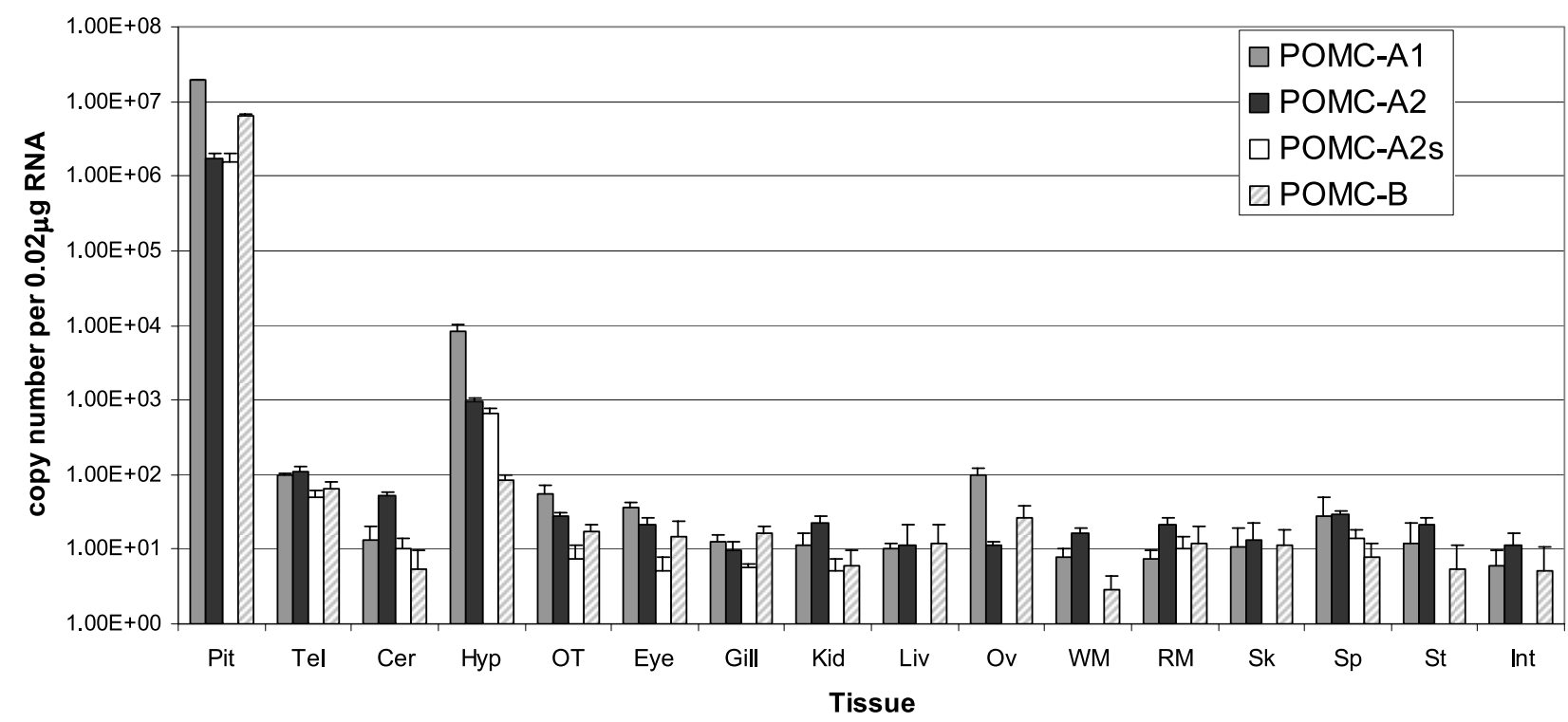

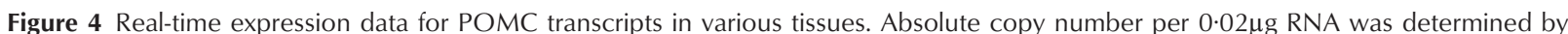
comparing cycle numbers with those from a serial dilution of plasmid containing a known copy number. Error bars represent the S.D. of the copy number. Pit, pituitary; Tel, telencephalon; Cer, cerebellum; Hyp, hypothalamus; OT, optic tectum; Kid, kidney; Liv, liver; Ov, ovary; WM, white muscle; RM, red muscle, Sk, skin; Sp, spleen; St, stomach; Int, intestine. 


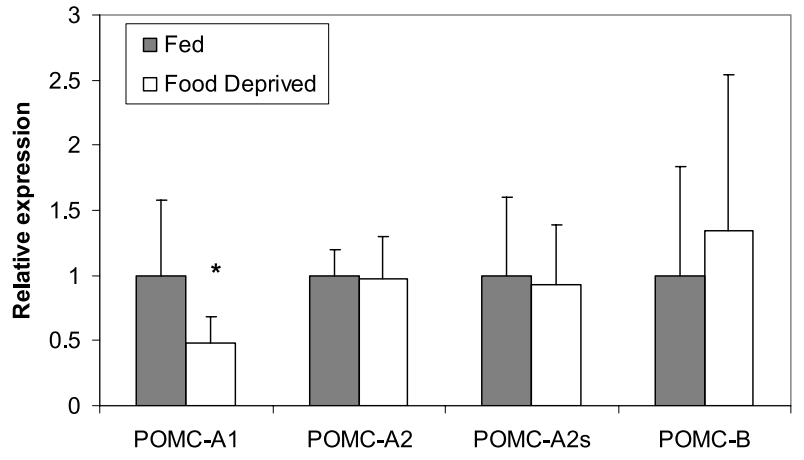

Figure 5 Relative expression of POMC transcripts in the hypothalamus between fed fish and fish deprived of food for 28 days. The relative standard curve method was used to determine the amount of transcript relative to the fed sample. Values are presented relative to the fed sample for each gene. The asterisk indicates a significant difference in the means of the normalized values $(P=0 \cdot 028)$.

The high degree of similarity of POMC-A1 and POMC-A2 is thus more consistent with a more recent duplication, specifically the salmonid genome duplication. It would also follow that POMC-B would be duplicated, but multiple copies of POMC-B were not identified in this study.

Genome duplication in teleosts is a well-studied phenomenon, but only recently have scientists presented unequivocal data that support genome duplication (Jaillon et al. 2004). Despite contrary theories, an increasing number of functional duplicate genes are being discovered (Nadeau \& Sankoff 1997, Prince \& Pickett 2002). It could be that many of the duplicated genes that have been discovered have significant physiological roles and thus it is advantageous to have redundancy or there could be other reasons why these genes persist. Evolution of novel function is one suggested reason why duplicate genes would persist, but the novelty could be subtle, such as tissue-specific expression (Coon et al. 1999) or development stage-specific expression (Gabillard et al. 2003) and may not be influenced by the coding sequence itself, but by promoter or regulatory elements upstream of the gene or, in genes such as the POMC gene, in its post-translational processing.

The high levels of POMC transcripts found in the pituitary are consistent with other reports of POMC expression in teleosts (Arends et al. 1998, GonzalezNunez et al. 2003, Varsamos et al. 2003, Karsi et al. 2004, Takahashi et al. 2005). In rainbow trout, POMC transcripts were detected in most of the other tissues examined, but the levels were low ( $<40$ copies per $0.02 \mu \mathrm{g}$ RNA) (Fig. 4). In barfin flounder (bf), bfPOMC-A was expressed only in the pituitary, but bfPOMC-B and bfPOMC-C transcripts were detected in many tissues using RT-PCR and Southern hybridization. In European sea bass, a few peripheral tissues (liver, gonad, and head kidney) were examined for POMC expression using real-time PCR, and the results are similar to those found in rainbow trout: low expression in the liver and head kidney and slightly more in the gonad (Varsamos et al. 2003). Hypothalamic or whole brain expression has not been examined in European sea bass. In catfish, several of the same tissues were examined and the kidney had relatively high expression compared with other tissues (Karsi et al. 2004). The stomach also contained higher levels of expression than the other peripheral tissues examined. However, in barfin flounder as well as in catfish, the hypothalamus was included with the rest of the brain tissues, so transcript levels may seem lower because of dilution with transcripts from the rest of the brain.

Differences in the abundance of the POMC transcripts in the hypothalamus in rainbow trout may be related to their functional differences. For example, expression of POMC-A1 responded to changes in energy balance by dropping $50 \%$ in fish deprived of feed for 28 days. Although we do not know into which peptides the hypothalamic POMC-A1 was translated, our findings are consistent with an $\alpha-\mathrm{MSH}-$ like activity, since a reduction in the appetite-inhibiting peptide $\alpha-\mathrm{MSH}$ is expected when energy balance becomes increasingly negative. The lack of POMC-A1 response to 14 days of feed deprivation suggests that this energy balance system in rainbow trout requires a considerable perturbation to respond. POMC-B expression was much lower in the hypothalamus than the other POMC transcripts (Fig. 4). Although, in the flounder, expression in response to food deprivation was not examined in POMC-A-like forms, Takahashi et al. (2005) reported that barfin flounder POMC-B-like transcript (called bfPOMC-C) did not respond to feeding status. It could be that POMC-B has lost its role in energy balance in the hypothalamus, and that gene duplication has allowed for different transcripts to evolve tissue-specific functions.

Expression of the different POMC transcripts could vary with life-history stage or in response to environmental conditions. Prior work on POMC in rainbow trout in different reproductive states revealed hypothalamic expression of POMC-B to be undetectable by Northern blot analysis in triploid or post-ovulated female rainbow trout but detectable in mature females (Salbert et al. 1992). In the present study, POMC-B transcript was detectable in the hypothalamus of immature female fish but was present at lower levels than the POMC-A transcripts (Fig. 4). Arends et al. (1998) found strain differences in the expression of POMC transcripts resulting from duplicated POMC genes in response to temperature stress, so it is likely that further experimentation involving multiple reproductive states or physiological treatments will reveal varied expression of the different transcripts.

In addition to the three distinct genes, a splice variant was also observed. This shorter form, POMC-A2s, was 
not as widely distributed as POMC-A2 in the rainbow trout examined (Fig. 4). However, the expression levels of all POMC transcripts were low in the peripheral tissues and the variance was high for the low copy number transcripts. It is also possible that POMC-A2s is expressed at a different life-history stage, under certain physiological conditions, in response to specific external conditions, or in tissues other than those examined.

The POMC gene encodes several important regulatory peptides which are known to be involved in critical and sometimes opposing functions; for example, $\alpha-\mathrm{MSH}$ and $\beta$-endorphin have opposing actions on feed intake. Regulation of these peptides is known to occur through tissue-specific, post-translational processing (Smith \& Funder 1988). In the present study, four different POMC transcripts resulting from three genes were identified. Differential expression and splicing of the various POMC genes in rainbow trout may permit an additional means of regulating these functions. Expression data suggest that these transcripts are being differentially expressed in rainbow trout as demonstrated by differential expression among tissues and in response to food deprivation. However, given the variety of functions of POMC peptides, expression levels cannot be correlated with function without further examination of the specific POMC peptides.

\section{Funding}

Funding for this research was provided by the United States Department of Agriculture, Agricultural Research Service. The authors declare that there is no conflict of interest that would prejudice the impartiality of this scientific work.

\section{References}

Amemiya Y, Takahashi A, Meguro H \& Kawauchi H 1999a Molecular cloning of lungfish proopiomelanocortin cDNA. General and Comparative Endocrinology 115 415-421.

Amemiya Y, Takahashi A, Suzuki N, Sasayama Y \& Kawauchi H 1999 b A newly characterized melanotropin in proopiomelanocortin in pituitaries of an elasmobranch, Squalus acanthias. General and Comparative Endocrinology 114 387-395.

Arends RJ, Vermeer H, Martens GJ, Leunissen JA, Wendelaar Bonga SE \& Flik G 1998 Cloning and expression of two proopiomelanocortin mRNAs in the common carp (Cyprinus carpio L.). Molecular and Cellular Endocrinology 143 23-31.

Banks WA, Kastin AJ, Huang W, Jaspan JB \& Maness LM 1996 Leptin enters the brain by a saturable system independent of insulin. Peptides 17 305-311.

Cheung CC, Clifton DK \& Steiner RA 1997 Proopiomelanocortin neurons are direct targets for leptin in the hypothalamus. Endocrinology 138 4489-4492.

Civelli O, Birnberg N \& Herbert E 1982 Detection and quantitation of pro-opiomelanocortin mRNA in pituitary and brain tissues from different species. Journal of Biological Chemistry 257 6783-6787.

Coon SL, Begay V, Deurloo D, Falcon J \& Klein DC 1999 Two arylalkylamine $\mathrm{N}$-acetyltransferase genes mediate melatonin synthesis in fish. Journal of Biological Chemistry 274 9076-9082.
Corpet F 1988 Multiple sequence alignment with hierarchical clustering. Nucleic Acids Research 16 10881-10890.

Elias CF, Lee C, Kelly J, Aschkenasi C, Ahima RS, Couceyro PR, Kuhar MJ, Saper CB \& Elmquist JK 1998 Leptin activates hypothalamic CART neurons projecting to the spinal cord. Neuron 21 1375-1385.

Friedman JM \& Halaas JL 1998 Leptin and the regulation of body weight in mammals. Nature $395763-770$.

Gabillard JC, Duval H, Cauty C, Rescan PY, Weil C \& Le Bail PY 2003 Differential expression of the two GH genes during embryonic development of rainbow trout Oncorhynchus mykiss in relation with the IGFs system. Molecular Reproduction and Development 64 32-40.

Gonzalez-Nunez V, Gonzalez-Sarmiento R \& Rodriguez RE 2003 Identification of two proopiomelanocortin genes in zebrafish (Danio rerio). Brain Research: Molecular Brain Research 120 1-8.

Jaillon O, Aury JM, Brunet F, Petit JL, Stange-Thomann N, Mauceli E, Bouneau L, Fischer C, Ozouf-Costaz C, Bernot A et al. 2004 Genome duplication in the teleost fish Tetraodon nigroviridis reveals the early vertebrate proto-karyotype. Nature 431 946-957.

Karsi A, Waldbieser GC, Small BC, Liu Z \& Wolters WR 2004 Molecular cloning of proopiomelanocortin cDNA and multi-tissue mRNA expression in channel catfish. General and Comparative Endocrinology 137 312-321.

Kitahara N, Nishizawa T, Iida K, Okazaki H, Andoh T \& Soma GI 1988 Absence of a gamma-melanocyte-stimulating hormone sequence in proopiomelanocortin mRNA of chum salmon Oncorhynchus keta. Comparative Biochemistry and Physiology B, Comparative Biochemistry 91 365-370.

Lee J, Danielson P, Sollars C, Alrubaian J, Balm P \& Dores RM 1999 Cloning of a neoteleost (Oreochromis mossambicus) pro-opiomelanocortin (POMC) cDNA reveals a deletion of the gamma-melanotropin region and most of the joining peptide region: implications for POMC processing. Peptides 20 1391-1399.

Nadeau JH \& Sankoff D 1997 Comparable rates of gene loss and functional divergence after genome duplications early in vertebrate evolution. Genetics 147 1259-1266.

Nakanishi S, Inoue A, Kita T, Nakamura M, Chang AC, Cohen SN \& Numa S 1979 Nucleotide sequence of cloned cDNA for bovine corticotropin-beta-lipotropin precursor. Nature 278 423-427.

Prince VE \& Pickett FB 2002 Splitting pairs: the diverging fates of duplicated genes. Nature Reviews: Genetics 3 827-837.

Ramos-Payan R, Aguilar-Medina M, Estrada-Parra S, Gonzalez YMJA, Favila-Castillo L, Monroy-Ostria A \& Estrada-Garcia IC 2003 Quantification of cytokine gene expression using an economical real-time polymerase chain reaction method based on SYBR Green I. Scandinavian Journal of Immunology 57 439-445.

Rexroad CE 3rd, Lee Y, Keele JW, Karamycheva S, Brown G, Koop B, Gahr SA, Palti Y \& Quackenbush J 2003 Sequence analysis of a rainbow trout cDNA library and creation of a gene index. Cytogenetic and Genome Research 102 347-354.

Saitou N \& Nei M 1987 The neighbor-joining method: a new method for reconstructing phylogenetic trees. Molecular Biology and Evolution 4 406-425.

Salbert G, Chauveau I, Bonnec G, Valotaire Y \& Jego P 1992 One of the two trout proopiomelanocortin messenger RNAs potentially encodes new peptides. Molecular Endocrinology 6 1605-1613.

Schwartz MW, Woods SC, Porte D Jr, Seeley RJ \& Baskin DG 2000 Central nervous system control of food intake. Nature 404 661-671.

Smith AI \& Funder JW 1988 Proopiomelanocortin processing in the pituitary, central nervous system, and peripheral tissues. Endocrine Reviews 9 159-179.

Swofford DL 1998 PAUP*. Phylogenetic Analysis Using Parsimony (*and Other Methods), version 4. Sunderland, Massachusetts: Sinauer Associates.

Takahashi A, Amemiya Y, Sarashi M, Sower SA \& Kawauchi H 1995 Melanotropin and corticotropin are encoded on two distinct genes 
in the lamprey, the earliest evolved extant vertebrate. Biochemical and Biophysical Research Communications 213 490-498.

Takahashi A, Amano M, Itoh T, Yasuda A, Yamanome T, Amemiya Y, Sasaki K, Sakai M, Yamamori K \& Kawauchi H 2005 Nucleotide sequence and expression of three subtypes of proopiomelanocortin mRNA in barfin flounder. General and Comparative Endocrinology 141 291-303.

Thompson JD, Gibson TJ, Plewniak F, Jeanmougin F \& Higgins DG 1997 The CLUSTAL_X windows interface: flexible strategies for multiple sequence alignment aided by quality analysis tools. Nucleic Acids Research 25 4876-4882.

Varsamos S, Wendelaar Bonga SE, Flik G, Quere R \& Commes T 2003 Cloning of a proopiomelanocortin cDNA from the pituitary gland of the sea bass (Dicentrarchus labrax) and assessment of mRNA expression in different tissues by means of real-time PCR. Journal of Endocrinology 176 405-414.

Volkoff H, Canosa LF, Unniappan S, Cerda-Reverter JM, Bernier NJ, Kelly SP \& Peter RE 2005 Neuropeptides and the control of food intake in fish. General and Comparative Endocrinology 142 3-19.

Received 7 November 2005

Accepted 17 November 2005

Made available online as an Accepted Preprint 25 November 2005 